\title{
Technology Knowledge in Marketing Ecosystems: a Framework and Research Agenda
}

\author{
Mary Ellen Gordon \\ School of Information Management \\ Victoria University of Wellington \\ Wellington, New Zealand \\ Email: maryellen.gordon@vuw.ac.nz \\ Jocelyn Cranefield \\ School of Information Management \\ Victoria University of Wellington \\ Wellington, New Zealand \\ Email: Jocelyn.Cranefield@vuw.ac.nz
}

\begin{abstract}
The practice of marketing has become increasingly technology-dependent, making organisations reliant on fragmented information systems that extend beyond organisational boundaries and requiring marketing professionals to develop technology-related knowledge and/or collaborate more closely with those who have it. Despite massive investment in marketing technology, there has been little academic research on the intersection between marketing and technology knowledge. Drawing on three examples, we illustrate how complex and IS-dependent the practice of marketing and marketing decision-making have become. We then analyse those examples through the lens of knowledge management. Specifically, we consider the differences between traditional and modern marketing ecosystems and the implications for knowledge work, knowledge management, and decision-making at the level of organisations and ecosystems. We propose a provisional conceptual framework for understanding how market, marketing and technology knowledge have become intertwined and propose a research agenda for examining that more closely.
\end{abstract}

Keywords knowledge management, marketing, marketing technology, ecosystems, technology knowledge 


\section{Introduction}

According to Gartner, as of this year, the amount that CMOs spend on technology will exceed the technology spending of CIOs (Sorofman and Virzi 2017). Furthermore, technology giants Google and Facebook generate most of their revenue by facilitating the marketing of other organisations through selling ads and supplying the data necessary to target those ads very precisely. Many smaller app developers also monetise their apps by showing ads for other organisations. The flourishing marketing technology (martech) sector, which helps facilitate this advertising technology (adtech) ecosystem as well as other forms of marketing automation, comprises more than 5000 organisations (Brinker 2017).

This paper discusses the transition from traditional to modern marketing ecosystems, the role that technology is playing in that transition, and the implications for knowledge workers. We distinguish between traditional and modern marketing ecosystems based on whether an organisation's marketing practices are similar to those organisations in their industry have been using for a long time (e.g., food manufacturing) or different from them (e.g., retailers that have embraced e-commerce). Modern marketing ecosystems also include types of organisations that didn't exist until recently and therefore also developed their marketing practices relatively recently (e.g., ride share companies or streaming music services).

Marketing has always used some technology and technology products have always been marketed, but never before have marketing and technology been as inter-twined as they are today. That has increased the need for marketers (knowledge workers in marketing ecosystems) to develop technology knowledge or to work more closely with those who have it. Much of this is being driven by growth in the availability of data. Day (2011) reports a widening gap between the traditional capabilities of the marketing function and its ability to deal effectively with the growth in market complexity and data volume: "Marketers are being challenged by a deluge of data that is well beyond the capacity of their organizations to comprehend and use. Their strategies are not keeping up with the disruptive effects of technology-empowered customers; the proliferation of media, channel, and customer contact points; or the possibilities for micro-segmentation" (p.183). According to Quinn et al. (2016), the evolving, increasingly digitalised marketplace, together with the impact of big data and advances in analytics have "precipitated a sense of crisis for marketers and the role of marketing within the firm" (p.2103).

One way in which that role is changing is the nature of marketing decision-making. Historically, that's involved a relatively small number of big decisions (e.g., What will we sell? Who will we target? How much will we charge?). Those decisions were made relatively infrequently, often after months of analysis. The same decisions still need to be made, but often in modern marketing ecosystems, they need to be made on a much larger scale (due to customisation), in real time or very close to it. For example, e-commerce retailers such as Amazon must decide which of the millions of products they offer to promote to a given visitor in a given moment. With real-time bidding, which has become an increasingly common way to buy ads, advertisers have less than a second to decide whether to bid to show an ad to a given user of a given app or Web-site at that exact moment, and if so, which ad to show. Some businesses with fixed quantities of perishable inventory, such as airlines and hotels, make pricing decisions throughout the day every day based on models comparing remaining inventory for a given time period to historical trends, sometimes also incorporating data about a specific customer.

Businesses such as those described in the previous paragraph have become highly reliant on complex, technology-intensive, highly-distributed ecosystems of internal and external knowledge workers, hardware, software and data to manage marketing processes and decisions. They use information systems that evolve rapidly, that extend beyond organisational boundaries (Quinn et al. 2016), and that involve many decisions but no central decision-maker. While Day (2011) has highlighted the need for organisations to build new adaptive marketing capabilities, we've found no studies about the nature of the working knowledge (Davenport and Prusak 1998) of technology required by organisations and individuals operating in modern marketing ecosystems, or how this differs from the knowledge work that is involved in more traditional marketing ecosystems.

This paper is motivated by a desire to explore these issues. It's largely a conceptual study, designed to help guide the design of subsequent research. We didn't conduct a formal data gathering exercise, but instead drew on the work experience of the first author to describe three examples that illustrate the extent to which modern marketing work relies on diverse combinations of knowledge and technologies. These examples are then reflected upon from the perspective of the knowledge management literature. Our reflections were guided by the questions, (a) what types of knowledge are required in modern marketing ecosystems? and (b) How is technology changing the nature of marketing practice? We employ an epistemology of practice view (Cook and Brown 1999; Cook and Wagenaar 2012; Newell 2015), to draw out commonalities and implications from the examples. This 
approach allowed us to combine an emic (insider) view (Pike 1967) with an etic (outsider) perspective (Pike 1967), to elicit a more abstract, theoretically-informed analysis of the examples. In qualitative research, the tension between etic and emic views has been described as an opportunity rather than a limitation (Olive 2014). Based on that combination of perspectives and analysis, we propose a highlevel framework for the interactions of three types of knowledge required in technologically-intensive marketing work, make a series of propositions and suggest an agenda for future research.

\section{Marketing Process Examples}

The examples described in this section are intended to illustrate the knowledge, skills, and technology required in three different marketing processes. They are based on participant observation by one of the authors and are set in technology organisations. They are intended to be illustrative of what's happening in modern marketing ecosystems and to provide insight into the direction that many marketing ecosystems may be heading.

\subsection{Example 1: Using Surveys to Generate Insights}

The first author previously led the team that created, implemented and managed the systems used to survey customers of a global technology company. Insights from such surveys are used to inform strategic and tactical marketing decisions. Implementing such surveys for a large, global company is a complex, technology-intensive process. It involves programming and testing questionnaires in survey software, sampling from a large customer database, sending survey invitations, collecting and storing responses, analysing responses using statistical software, and visualising results for decision-makers. These processes are highly automated and require careful project management.

One important component of project management is checking to make sure all aspects of the process are working as expected. In situations in which they aren't, the complexity can escalate. One such incident occurred when the response rate for surveys of Chinese customers dropped dramatically over a very short period of time. Determining why and how to fix it required considerable technologyrelated detective work. The survey software had to be checked for problems, as did the system for emailing survey invitations. Customers whose responses had come in had to be compared to those whose did not to see if there were differences based on IP address, e-mail domain, etc. Checks needed to be done to see if the rate of e-mail opens had also dropped or just the survey response rate and to see if any Chinese ISPs were experiencing widespread problems. Further investigations were done to see if delivery of other types of content to people in China were affected. In the end, network traces revealed that the survey software vendor was making use of a Google Hosted JavaScript library, and while Google is blocked by China's firewall, that particular library had not been previously, but all of a sudden was. The survey software vendor making a change to host that library internally rectified the problem; however, the survey software vendor themselves were unaware of the problem until it was called to their attention.

\subsection{Example 2: Using Data to Craft and Target Advertising}

To acquire new customers or to get existing customers to buy more, companies need to use messaging that's persuasive to the target audience based on what's important to them. Historically, survey research has been used to determine how interests, preferences and behaviours vary across groups such as mothers, CEOs or millennials. That information is used by advertising agencies who create ads intended to resonate with a prototypical person in the target group(s). Measurement companies, such as Nielsen, identify what types of people specific TV shows, magazines, radio stations, etc. tend to attract, and media buyers select the combination that best matches the advertisers' target audience.

As digital media has become more pervasive, the ecosystem for creating and targeting ads and measuring advertising effectiveness has become more complex and more technology- and data-driven. As before, marketers are trying to understand customers and potential customers as well as they can to craft a message they'll see (because of the media they're interacting with) and find persuasive (because the content resonates with them). But modern marketers can base decisions on what ads to show to whom based on individuals' actual behavioural data, such as transaction data, Web analytics data, app analytics data, geo-location data from WiFi networks and ISPs, etc.

That's important because people aren't just one thing and don't necessarily conform to group stereotypes. Someone may be a mother, a CEO and a millennial. Even though on average, middle-age men tend to be sports fans, a given middle-age man may hate sports. Ads that are crafted and targeted based on more holistic views of consumers are more likely to be effective. 


\subsection{Example 3: Using Machine Learning to Bid for Ads}

One of the consequences of the combination of more digital media and greater availability of data that can be used for targeting advertising has been creation of an advertising technology (adtech) sector, made up of organisations that enable the type of precision-targeting described in the previous example. Within that sector ad exchanges have emerged to allow publishers, such as app developers, to offer to show an ad to a given user of their app (for a fee) and allow advertisers to purchase that right. This happens via an auction (to find the advertiser willing to pay the most to expose that user to an ad at that moment) that happens a fraction of a second before the winning ad displays on a user's screen.

To enable billions of auctions to happen each day at that speed, demand-side platforms, representing advertisers, develop machine learning models to decide what impressions to bid on, how much to offer for them, and which ad to show if they win. The machine learning aspect of this is challenging, and it also requires very good information architecture to make decisions quickly enough to participate in the auction and to serve the selected ad quickly enough for it to be displayed.

The system just described is already a highly-complex one relying on a variety of software, hardware, data and technology skills. But the system can have a narrow focus on optimising the return for each individual impression. Maximising the ROI of industry participants can also require macro-level analysis that considers the overall supply of and demand for impressions. This analysis often reveals imbalances. For example, one such analysis of one ad exchange in 2013 (Gordon 2013) showed an over-supply of available impressions for music lovers, but an under-supply of impressions that could be used to show ads to people who are into fashion or food and dining. Having that information enables industry participants to self-correct - in that example, by ad sales teams for demand-side platforms seeking out advertisers who want to reach music lovers and supply-side platforms seeking out publishers with food and fashion content to provide ad space for their platforms.

\section{Theoretical Commentary: Framing the Analysis}

The knowledge management (KM) literature is characterised by a dual conception of knowledge and how it should be managed (Newell 2015). Much KM literature takes an epistemology of possession perspective (Cook and Brown 1999; Newell 2015), viewing knowledge as an asset or resource to manage. In this tradition, IT is typically viewed as a tool or a container for managing knowledge. Our analysis of the marketing process examples employs the complementary epistemology of practice view (Cook and Brown 1999; Cook and Wagenaar 2012; Newell 2015), in which knowledge is seen as being embedded in human action and as being of value insofar as it is useful in practice. Davenport and Prusak's (1998) seminal study of working knowledge within this tradition defines knowledge as, "a fluid mix of framed experience, values, contextual information, and expert insight that provides a framework for evaluating and incorporating new experiences and insight...." (p.5). Similarly, Orlikowski (2002) describes knowledge, or knowing, as being "an ongoing social accomplishment, constituted and reconstituted as actors engage the world of practice" (p. 249).

According to the epistemology of practice view, knowledge is closer to action than data or information, so is critical in informing decisions (Davenport and Prusak 1998). Cook and Wagenaar (2012) coin the term actionable understanding to emphasise this concept of knowledge as a critical tool of practice. The epistemology of practice view recognises that IT may be influential in knowledge work (Newell, 2015). This view of knowledge management emphasises managing interactions of knowledge workers, and understanding the actions, interactions and roles involved (Hacker et al. 2017; Newell et al. 2009).

Within the KM literature, a prior study (Hanvanich et al. 2003) applied a KM lens to conceptualise marketing knowledge. The authors propose a model of marketing knowledge based around three marketing processes: product development management (PDM), supply chain management (SCM) and customer relationship management (CRM). Even in 2003, some technology was used to support those processes, yet technology knowledge does not feature in this model.

In 2003 marketing technology was significantly less pervasive and mature than it is now, and importantly, it was more isolated from marketing knowledge workers than it is now. For example, in 2003, marketing staff might have used a customer relationship management system, but it would have been designed, built, and maintained by IT knowledge workers and used not that differently from how marketers a generation before may have used a Rolodex. Marketers today still use customer relationship management systems, but they are more likely to be involved in the design, building, and maintenance of those systems (in part because that's likely to just be customisation of a software as a service solution) and the CRM system is much more likely to need to be integrated with other technology that marketers need to use, such as campaign management systems. In 2017, the leading 
provider of external (SaaS) CRM systems is Salesforce, and as of August 2017, 284 different marketing-related apps integrated with Salesforce to enable marketing knowledge workers to do things such as send customers e-mail and connect with them on social media (Salesforce.com 2017).

Song et al. (2005) studied the relationship between technology and marketing-related capabilities in joint ventures, using the resource-based view. They found that in highly technologically-turbulent joint venture environments, the impact of marketing-related capabilities on performance increased with the level of technology-related capabilities, and the impact of technology-related capabilities on performance increased with the level of marketing-related capabilities. In other words, in highly technologically-turbulent environments, the greater the capability in one area (marketing- or technology-related), the higher the impact on performance of the other capability (p.271).

The examples show that modern marketers need to interact extensively with others in their own organisations, but also with people working in other parts of their ecosystems (vendors, customers, intermediaries such as those who run various types of exchanges and marketplaces, etc.). This means they need to be skilled at negotiating boundaries within and between organisations. Boundaries are of interest in knowledge management owing to their dual role as enablers and barriers: Innovation typically occurs in the boundaries between disciplines, yet there are many challenges associated with the flow of knowledge across various types of boundaries (Carlile 2002, 2004; Newell 2015). Boundaries exist between structural divisions, communities of practice, organisations and knowledge domains. Carlile (2004) proposes a framework of three conceptual boundary categories, each associated with a different bridging mechanisms: (a) syntactic boundaries, which are spanned by a common lexicon, can be bridged by straightforward knowledge transfer; (b) semantic boundaries involve differences in meanings, so require a process of translation to be bridged; and (c) pragmatic boundaries, which involve differing interests, require a transformation process in order to be bridged. There have been calls for more flexible approaches to how boundaries are conceived in IS research (Lindgren et al. 2008; Santos and Eisenhardt 2005; Swart et al. 2011). For example, Lindgren et al. highlight the need to recognise that there may be multiple co-existing boundaries.

Our inductive analysis of the knowledge employed in the examples was sensitized by an awareness of theory about the multi-dimensional nature of knowledge required in the teaching profession, and the integration of technological knowledge in that field (Angeli and Valanides 2008, 2013; Mishra and Koehler 2006). Teachers are seen as simultaneously applying multiple domains of knowledge when thinking about and performing their work. Shulman $(1986,1987)$ revitalised understanding of teaching knowledge by proposing the category of pedagogical content knowledge, knowledge of the relationship between content, pedagogy and learners. In 2006, recognising the importance of technology and its affordances, Mishra and Koehler built on Shulman's model to incorporate technological knowledge, which they argue is critical to the success of teaching and the creation of learning opportunities. Their TPACK model (Mishra and Koehler 2006) is based on a Venn diagram with three overlapping circles that show the interaction of (a) pedagogical knowledge, (b) content knowledge (CK; knowledge about the subject matter being taught), and (c) technological knowledge (TK) that is required by people working in that profession. The resulting categories of knowledge have formed the basis of subsequent research in professional learning and development in teaching. The framework was novel in its recognition of technological knowledge as a critical aspect of professional domain knowledge that contributed to the effectiveness of teaching, helping move the focus of educators and researchers beyond viewing technology as an add-on.

While influenced by the TPACK approach, our analysis follows Orlikowski (2002) in recognising that knowledge and competence are likely to be distributed amongst multiple players rather than found in a single professional. Orlikowski (2002) found that "the competence to do global product development is both collective and distributed, grounded in the everyday practices of...members" (p. 249).

\section{Analysis and Framework}

In order to identify patterns across the three examples, we broke each process into steps. We coded each of step based on: (a) the type(s) of knowledge workers involved (internal marketing, internal IT, other internal, external), (b) the type(s) of knowledge applied, (c) hardware, software, and data used, and (d) the type(s) of boundaries involved (syntactic, semantic or pragmatic).

Our development of sub-categories of knowledge was informed by both the examples and the TPACK framework and were: knowledge of the specific market, general knowledge about marketing, and technology-related knowledge. Market knowledge can be thought of as broadly analogous to content knowledge in the TPACK model, and marketing knowledge can be thought of as analogous to 
pedagogical knowledge, with the former being about the subject matter and the latter being about the practice of engaging with the subject matter. Market knowledge includes things such as understanding customer preferences and how those vary. Marketing knowledge includes things such as how to measure advertising effectiveness or create a customer satisfaction survey. Technology knowledge is that required to complete specific marketing tasks, such as using CSS to change the look of a Web site.

The three knowledge domains are shown in figure 1. As shown on the left side, all three domains have probably always existed and there have probably always been overlaps between them. But, as shown in the right side of the figure, the size of the technology domain has grown, it now overlaps more with the market and marketing domains (as shown in grey), and it has greater importance in modern marketing ecosystems than traditional marketing ecosystems (as shown by the proportion of the other domains covered in grey in the right side of the figure compared to the left). Importance could be defined as the frequency with which that type of knowledge is used or by the value created through the application of that type of knowledge. This is formally expressed in the first proposition below.

Proposition 1: Technology knowledge is more important within modern marketing ecosystems than in more traditional marketing ecosystems.

\section{Knowledge Domains}

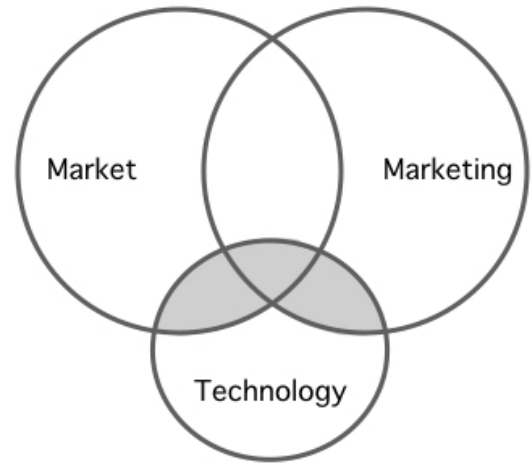

Traditional Marketing Ecosystem

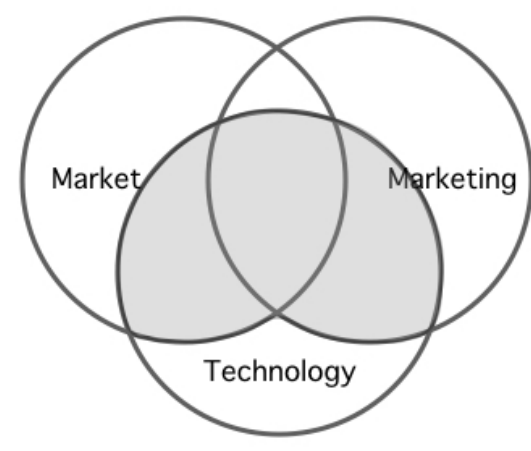

Modern Marketing Ecosystem

Figure 1: Marketing Knowledge Domains and Evolution

The examples suggest that in modern marketing ecosystems (as opposed to more traditional ecosystems) when technology knowledge is applied it is more frequently applied concurrently with marketing or market knowledge. For example, marketing knowledge workers in traditional ecosystems use technology such as e-mail and PowerPoint, but those are used primarily to communicate knowledge about a market or a marketing activity. In contrast, in modern marketing ecosystems, technology is more likely to be involved in both the creation and communication of knowledge about the market and marketing. For example, as described in the second example, data from transactions, Websites, apps, ISPs or WiFi networks can provide real-time intelligence about a particular market and A/B testing can provide immediate feedback on the effectiveness of different marketing tactics. That concurrent use of different types of knowledge means that either knowledge workers need to possess knowledge across more domains or that they need to work very closely with colleagues who have the complementary type of knowledge.

Proposition 2: In modern marketing ecosystems, technology knowledge is more often used concurrently with market or marketing knowledge than in more traditional marketing ecosystems.

Similarly, based on the examples, we believe that modern marketing ecosystems are more likely to involve use of more complex and varied information systems (including hardware, software and data) to execute tasks. For example, marketing knowledge workers have used statistical software to analyse survey results for a long time, but as shown in the first example, surveys in modern marketing information systems incorporate a wide variety of additional hardware, software and data. Coordinating all of those requires marketing knowledge workers to have greater breadth and depth of 
knowledge since they not only need to know how each part of the system works but also how to integrate and trouble-shoot those different parts.

Proposition 3: Compared to traditional marketing ecosystems, processes within modern marketing ecosystems are more likely to involve use of more complex and varied information systems (including hardware, software and data).

Knowledge work in modern marketing ecosystems also seems likely to require more spanning of semantic and pragmatic boundaries compared to knowledge work in traditional ecosystems. Since knowledge workers in modern marketing ecosystems need to work with information systems that include many components (software, hardware, and data) to do their work, that's likely to bring them into contact with knowledge workers from other parts of their own organisations and from other organisations within their broader ecosystem. Differences in interpretation, meaning, and interests are likely to arise in those situations because of the different backgrounds and incentives of the other knowledge workers. For instance, in the third example, data scientists prioritised optimising that particular model; whereas marketing staff were more focussed on the broader objective of growing the market and maximising overall profit.

Proposition 4: Compared to traditional marketing ecosystems, modern marketing ecosystems require more spanning of semantic and pragmatic boundaries compared to knowledge work in traditional ecosystems.

A final pattern that we discerned from our examples is the extent to which challenges in the marketing domain drive the development of technology knowledge. For example, technology knowledge developed for producing precise, customised deliverables at high volume that was part of the survey automation process described in the first example was useful for others in the organisation and technology-related knowledge about machine learning acquired by companies such as Google to do things such as target ads as described in the second and third examples has since been applied to other areas that extend well beyond marketing. This greater tendency for marketing to drive technology development is probably, at least in part, a consequence of the greater overlap between marketing and technology as shown in figure 1. That greater overlap provides greater need for technologists to solve marketing problems, and in doing so to create solutions that also apply outside of marketing.

Proposition 5: Marketing needs are more frequently catalysts for technology knowledge advances in modern marketing ecosystems compared to traditional marketing ecosystems.

\section{Research Agenda and Discussion}

The analysis presented in the previous section illustrates some of the knowledge management and decision-making issues that arise in modern marketing ecosystems, but a lot of additional work remains to further explore, explain, and quantify this large and important area of knowledge work, decision-making and technology spending. This section proposes a research agenda for that process.

\subsection{Depth Interviews about a specific marketing process}

The conceptual framework proposes that knowledge workers in marketing ecosystems rely primarily on knowledge in three domains: market, marketing, and technology. We plan to confirm this through interviews with the knowledge worker(s) involved in a particular marketing process at twelve organisations. Those interviews will also be used to further explore differences between the types of knowledge used in modern marketing ecosystems compared to more traditional ecosystems, as half of the organisations will be selected from the former and half from the latter. Our expectation, as expressed in proposition 1, is that use of technology-related knowledge will be more prevalent and more important in modern marketing ecosystems compared to traditional ecosystems. We also expect more modern ecosystems to require more concurrent use of knowledge from different domains (as expressed in proposition 2) and greater use of software, hardware and data (as expressed in proposition 3).

As illustrated through the examples and implied by figure 1, marketing knowledge workers frequently need to collaborate with knowledge workers in other parts of their organisation and in other organisations. This implies a greater need to span boundaries between different teams within an organisation and between organisations. Boundary spanning within marketing processes will also be investigated during the interviews described above. Boundary spanners are individuals who connect 
different settings or contexts and who understand and bridge their cultures and norms (Awazu 2004; Levina and Vaast 2005; Prusak and Cross 2002). Interviewing multiple people from the same organisation involved in a given marketing process will help to further elaborate the extent and nature of boundaries being negotiated and the ways they may be crossed. As discussed in the previous section and expressed in proposition 4, the expectation is that this will reveal more spanning of semantic and pragmatic boundaries in more modern marketing ecosystems.

One implication of marketing ecosystems spanning organisational boundaries appears to be that they may end up being supported by information systems that emerge from the decisions, actions and reactions of multiple parties as opposed to being centrally planned or controlled. For example, the survey information system described in the first example involved hardware, software, and data controlled by a variety of internal teams, external vendors and other external parties (e.g., ISPs used by customers, and Google hosting a JavaScript Library used by the survey software vendor). Using such systems effectively is likely to require different types of knowledge than using more traditional information systems. In particular, knowledge about the structure of such systems seems less likely to be codified and more prone to change.

\subsection{Ethnography exploring whether I how marketing needs influence technology development}

Proposition 5 proposes that knowledge development in the technology domain may be driven by marketing needs in modern marketing ecosystems. It would be interesting to investigate when and how this happens and what types of marketing needs spur technology knowledge development. This type of process seems most likely to occur at companies such as Google, Facebook, and Amazon, which are heavily dependent on marketing activities for their revenue and are also major developers of new technology. One way to explore this area would be to do ethnographic research at such companies. We plan to do that in the future.

\section{Conclusions}

This paper has explored the increasing co-dependency of marketing and technology from a knowledge management perspective and identified three critical domains of knowledge required to execute marketing processes. Testing the propositions introduced and executing the research agenda proposed still requires a lot of additional work, but the volume of marketing spending on technology and the impact of marketing needs on technology development demonstrates why that work is so important.

\section{References}

Angeli, C., and Valanides, N. 2008. "TPCK In Pre-Service Teacher Education: Preparing Primary Education Students To Teach With Technology," In AERA annual conference, New York.

Angeli, C., and Valanides, N. 2013. "Technology Mapping: An Approach For Developing Technological Pedagogical Content Knowledge," Journal of Educational Computing Research, 48(2), 199-221.

Awazu, Y. 2004. "Informal Network Players, Knowledge Integration, And Competitive Advantage," Journal of Knowledge Management, 8(3), 62-70.

Brinker, S. 2017. Marketing Technology Landscape (Martec 5000) Chief Marketing Technologist Blog Retrieved from: http://cdn.chiefmartec.com/wpcontent/uploads/2017/05/marketing technology landscape 2017 slide.jpg 17 August, 2017.

Carlile, P. R. 2002. "A Pragmatic View Of Knowledge And Boundaries: Boundary Objects In New Product Development," Organization Science, 13(4), 442-455.

Carlile, P. R. 2004. "Transferring, Translating, And Transforming: An Integrative Framework For Managing Knowledge Across Boundaries," Organization Science, 15(5), 555-568.

Cook, S. D., and Brown, J. S. 1999. "Bridging Epistemologies: The Generative Dance Between Organizational Knowledge And Organizational Knowing," Organization Science, 10(4), 381400 .

Cook, S. N., and Wagenaar, H. 2012. "Navigating The Eternally Unfolding Present: Toward An Epistemology Of Practice," The American Review of Public Administration, 42(1), 3-38. 
Davenport, T. and Prusak, L. 1998. Working Knowledge: How Organizations Manage What They Know, Cambridge, MA: Harvard Business School Press.

Day, G. S. 2011 “Closing The Marketing Capabilities Gap,” Journal of Marketing (74:5), pp. 183-195.

Gordon, M. E. 2013. "Spoiler Alert: Don Draper Is Dead, And Mobile, Big Data, And RTB Killed Him.” http://web.archive.org/web/20131222190147/http://blog.flurry.com/bid/100784/spoiler-alertdon-draper-is-dead-and-mobile-big-data-and-rtb-killed-him?

Hacker, J.; Bodendorf, F.; Lorenz, P. 2017. "Helper, Sharer or Seeker? - A Concept to Determine Knowledge Worker Roles in Enterprise Social Networks," in Leimeister, J.M.; Brenner, W. (Hrsg.): Proceedings der 13. Internationalen Tagung Wirtschaftsinformatik (WI 2017), St. Gallen, S. 668-682

Hanvanich, S., Dröge, C., and Calantone, R. 2003. "Reconceptualizing the Meaning and Domain of Marketing Knowledge," Journal of Knowledge Management, 7(4), 124-135.

Levina, N., and Vaast, E. 2005. "The Emergence of Boundary Spanning Competence In Practice: Implications For Implementation And Use of Information Systems," MIS Quarterly, 29(2), 335363.

Lindgren, R., Andersson, M., and Henfridsson, O. 2008. "Multi-Contextuality In Boundary-Spanning Practices," Information Systems Journal, 18(6), 641-661.

Mishra, P. and Koehler, M.J., 2006. Technological Pedagogical Content Knowledge: A Framework for Teacher Knowledge. Teachers College Record, 108(6), p.1017.

Newell, S., Robertson, M., Scarbrough, H., Swan, J. 2009. Managing Knowledge Work and Innovation. Palgrave Macmillan, Basingstoke.

Newell, S. 2015. "Managing Knowledge And Managing Knowledge Work: What We Know And What The Future Holds," Journal of Information Technology, 30(1), 1-17.

Olive, J. L. 2014. "Reflecting On The Tensions Between Emic And Etic Perspectives In Life History Research: Lessons Learned," In Forum Qualitative Sozialforschung/Forum: Qualitative Social Research (Vol. 15, No. 2).

Orlikowski, W. J. 2002. "Knowing in Practice: Enacting A Collective Capability In Distributed Organizing," Organization Science, 13(3), 249-273.

Pike, K. L. 196). Language in Relation To A Unified Theory Of The Structures Of Human Behavior (2nd ed.). The Hague: Mouton

Prusak, L., and Cross, R. 2002. "The People Who Make Organizations Go - Or Stop," Harvard Business Review, 80(6), 104-112 (Reprint Ro206G).

Quinn. L, Dibb, S., Simkin, L., Canhoto, A., and Analogbei, M. (2016),"Troubled Waters: The Transformation Of Marketing In A Digital World," European Journal of Marketing, Vol. 50 Iss 12 pp. 2103-2133 http://dx.doi.org/10.1108/EJM-08-2015-0537

Salesforce.com, 2017. https://appexchange.salesforce.com/category/marketing retrieved 17 August, 2017.

Santos, F., and Eisenhardt, K. 2005. "Organizational Boundaries and Theories of Organization," Organization Science, 16(5), 491-508.

Shulman, L. S. 1986. "Those Who Understand: Knowledge Growth in Teaching," Educational Researcher, 15 (2), 4-14.

Shulman, L. S. 1987. "Knowledge and Teaching: Foundations of the New Reform," Harvard Education Review, 57 (1), 1-21.

Song, M., Droge, C., Hanvanich, S., and Calantone, R. 2005. "Marketing And Technology Resource Complementarity: An Analysis Of Their Interaction Effect In Two Environmental Contexts," Strategic Management Journal, 26(3), 259-276.

Sorofman, J and Virzi, AM 2017. CMO Spend Survey 2016 - 2017, Gartner: https://www.gartner.com/webinar/3390517

Swart, J., van den Hooff, B., and van Baalen, P. 2011. Connecting Worlds. Management Learning, 42(4), 371-377. 


\section{Copyright}

Copyright: (C) 2017 Mary Ellen Gordon and Jocelyn Cranefield. This is an open-access article distributed under the terms of the Creative Commons Attribution-NonCommercial 3.0 Australia License, which permits non-commercial use, distribution, and reproduction in any medium, provided the original author and ACIS are credited. 